\title{
Direct laser interference patterning for decreased bacterial attachment
}

Denise Guenther, Jaoine Valle, Saioa Burgui, Carmen Gil, Cristina Solano, et al.

Denise Guenther, Jaoine Valle, Saioa Burgui, Carmen Gil, Cristina Solano, Alejandro Toledo-Arana, Ralf Helbig, Carsten Werner, Inigo Lasa, Andrés F. Lasagni, "Direct laser interference patterning for decreased bacterial attachment," Proc. SPIE 9736, Laser-based Micro- and Nanoprocessing X, 973611 (4 March 2016); doi: 10.1117/12.2216065

SPIE. Event: SPIE LASE, 2016, San Francisco, California, United States 


\title{
Direct Laser Interference Patterning for decreased bacterial attachment
}

\author{
Denise Guenther*a,b Jaoine Valle ${ }^{\mathrm{c}}$, Saioa Burgui ${ }^{\mathrm{c}}$, Carmen Gil ${ }^{\mathrm{c}}$, Cristina Solano ${ }^{\mathrm{c}}$, Alejandro Toledo- \\ Arana $^{\mathrm{c}}$, Ralf Helbig ${ }^{\mathrm{d}}$, Carsten Werner ${ }^{\mathrm{d}}$, Inigo Lasa ${ }^{\mathrm{c}}$, Andrés F. Lasagni ${ }^{\mathrm{a}, \mathrm{b}}$ \\ aInstitute for Manufacturing Technology, Technische Universität Dresden, George-Bähr-Str. 3c, \\ 01062 Dresden, Germany; ${ }^{b}$ Fraunhofer IWS, Winterbergstr. 28, 01277 Dresden, Germany; \\ ${ }^{c}$ Agrobiotechnology Institute, Universidad Publica Navarra, Campus de Arrosadia Mutilva Baja, \\ 31192 Navarra, Spain; 'Leibniz Institute of Polymer Research Dresden, Hohe Str. 6, 01069 Dresden, \\ Germany
}

\begin{abstract}
In the past 15 years, many efforts were made to create functionalized artificial surfaces showing special anti-bacterial and anti-biofouling properties. Thereby, the topography of medical relevant materials plays an important role. However, the targeted fabrication of promising surface structures like hole-, lamella- and pyramid-like patterns with feature sizes in the sub-micrometer range in a one-step process is still a challenge. Optical and e-beam lithography, molding and selfassembly layers show a great potential to design topographies for this purpose. At the same time, most of these techniques are based on sequential processes, require masks or molds and thus are very device relevant and time consuming. In this work, we present the Direct Laser Interference Patterning (DLIP) technology as a capable method for the fast, flexible and direct fabrication of periodic micrometer- and submicrometer structures. This method offers the possibility to equip large plain areas and curved devices with 1D, 2D and 3D patterns. Simple 1D (e.g. lines) and complex 3D (e.g. lamella, pillars) patterns with periodic distances from $0.5 \mu \mathrm{m}$ to $5 \mu \mathrm{m}$ were fabricated on polymeric materials (polyimide, polystyrene). Subsequently, we characterized the adhesion behavior of Staphylococcus epidermidis and $S$. aureus bacteria under in vitro and in vivo conditions. The results revealed that the topographies have a significant impact on bacteria adhesion. On the one side, one-dimensional line-like structures especially with dimensions of the bacteria enhanced microbe attachment. While on the other hand, complex three-dimensional patterns prevented biofilm formation even after implantation and contamination in living organisms.
\end{abstract}

Keywords: Patterned surfaces; Polymers; Direct Laser Interference Patterning; Biofilm; Adhesion; Staphylococcus aureus; Staphylococcus epidermidis; Anti-bacterial

\section{INTRODUCTION}

Lately, the prevention of bacterial adhesion by inactivating bacteria after contacting the surface (contact killing) or alternatively, by repelling bacterial cells from attachment (anti-bacterial) has gained more prominence ${ }^{[1]}$. In most cases, colonization with bacteria has an adverse effect on the functionality of the surface, such as decreased performance or loss of medical implants, clogging of industrial pipes and tubing, and contamination of food manufacturing surface. Strategies to prevent and combat bacterial adhesion and proliferation to technical surfaces include chemical modifications with e.g. antibacterial agents (antibiotics, antimicrobial peptides, alkyl chains, silver, copper, detergents) and physical modification of the surface topography ${ }^{[2,3]}$. However, chemical modifications very often lead to toxicity due to the release of the chemical compounds. Furthermore, antibiotics lose their functionality over time and/or bacteria rapidly evolve multi-resistance to them.

Hence, the modification of surface topographies for creating anti-biofouling properties is receiving greater consideration ${ }^{[4,5]}$. First approaches to create specific surface topographies were mechanical roughening and polishing techniques with which it was possible to modulate bacteria attachment behavior ${ }^{[6-10]}$.

*denise.guenther1@tu-dresden.de; phone +49 351463 34976; fax +49 351463 37755; www.tu-dresden.de

Laser-based Micro- and Nanoprocessing X, edited by Udo Klotzbach, Kunihiko Washio, Craig B. Arnold, Proc. of SPIE Vol. 9736, 973611 - @ 2016 SPIE · CCC code: 0277-786X/16/\$18 · doi: 10.1117/12.2216065 
It was found out, that on topographically modified surfaces bacteria are forced to span the distance between each topographical feature for developing cell-cell interactions and thus, for the survival of the bacterial colony.

Recently, techniques such as optical lithography, microcontact printing, and electron or ion beam lithography have been used to fabricate periodic and aperiodic micro- and/or nanopatterns with well-defined and reproducible dimensions and shapes that allow the fabrication of periodic microstructures with well-defined and reproducible dimensions and

shapes ${ }^{[1-18]}$. However, these approaches require multiple steps and long processing times to treat substrates, especially if large areas have to be processed. As a complementary alternative to these methods, the Direct Laser Interference Patterning (DLIP) technology provides a new strategy to generate complex periodic micro- and nanotopographies on different materials such as polymers, metals, and ceramics ${ }^{[15-17]}$. With the DLIP it is possible to process fairly large flat areas as well as complex substrate geometries within a short period of time (up to $0.7-0.9 \mathrm{~m}^{2} / \mathrm{min}$ ) ${ }^{[19]}$. Furthermore, this method enables the fabrication of complex structures by systematically varying the dimensions of the gratings superimposed upon each other ${ }^{[20]}$.

In this study, we patterned polyimide (PI) and polystyrene surfaces (PS) with periodical line- (1D), pillar-like (2.5D) and a complex combination of lamella- and line-like structures (3D) by applying the Direct Laser Interference Patterning technique. Confocal as well as scanning electron microscopy methods were used to investigate the topography of the laser treated samples. Afterwards, the superficially modified samples together with non-patterned substrates of the same material were used for in vitro bacterial adhesion tests with Staphylococcus epidermidis and S. aureus bacteria under static flow conditions. Furthermore, we conducted in vivo studies on selected samples. Thereby, biofilm formation after contamination prior and post implantation was investigated. Statistical analysis of the bacterial attachment experiments was performed by one-way analysis of variance combined with the Bonferroni multiple post-hoc test or by the MannWhitney test, with $\mathrm{R} \leq 0.05$ considered significant (GraphPad Instat, version 5).

\section{EXPERIMENTAL}

\subsection{Laser patterning of polystyrene substrates}

Polyimide (PI, Kapton ${ }^{\circledR}$ ) films with a thickness of $125 \mu \mathrm{m}$ as well as two different polystyrene (PS) substrates with thicknesses of $125 \mu \mathrm{m}$ (biaxial orientated) and $1.2 \mathrm{~mm}$ were used. Both materials were purchased from Goodfellow $\mathrm{GmbH}$ (Bad Nauheim, Germany). Generally, polymers strongly absorb UV light ${ }^{[21]}$. Due to pendant phenyl groups at its backbone, PS strongly absorbs UV laser light with wavelengths below $300 \mathrm{~nm}\left(\alpha_{248}=6.3 \times 10^{3} 1 / \mathrm{cm}\right)^{[22]}$. In contrast, PI already exhibits high absorption at $355 \mathrm{~nm}\left(\alpha_{355}=0.36 \times 10^{5} 1 / \mathrm{cm}\right)$. Thus, we used a high-power pulsed, frequency tripeled and quadrupled Nd:YAG laser (Quanta Ray, Spectra Physics) emitting a beam with wavelengths of $\lambda=355 \mathrm{~nm}$ and $266 \mathrm{~nm}$ to pattern the materials. The samples were irradiated with $10 \mathrm{~ns}$ pulses at a frequency of $10 \mathrm{~Hz}$. For obtaining 1D line-like structures, the experimental set-up shown in Figure 1(a) was applied.

A beam splitter configuration (two beams) was used to obtain a line-like interference pattern (see Figure 1(c)). The spatial period P was varied from 0.5 to $5.0 \mu \mathrm{m}$ by keeping a constant laser wavelength (PI: $355 \mathrm{~nm}$, PS: $266 \mathrm{~nm}$ ) and varying the angle of incidence $2 \alpha$ between the interfering laser beams following:

$$
P=\frac{\lambda}{2 \sin \alpha}
$$

For obtaining a $2.5 \mathrm{D}$ and 3D structures, the samples were rotated by an angle of $90^{\circ}$ between two subsequent laser shots. All experiments were performed at ambient conditions of pressure and temperature. 
(a)
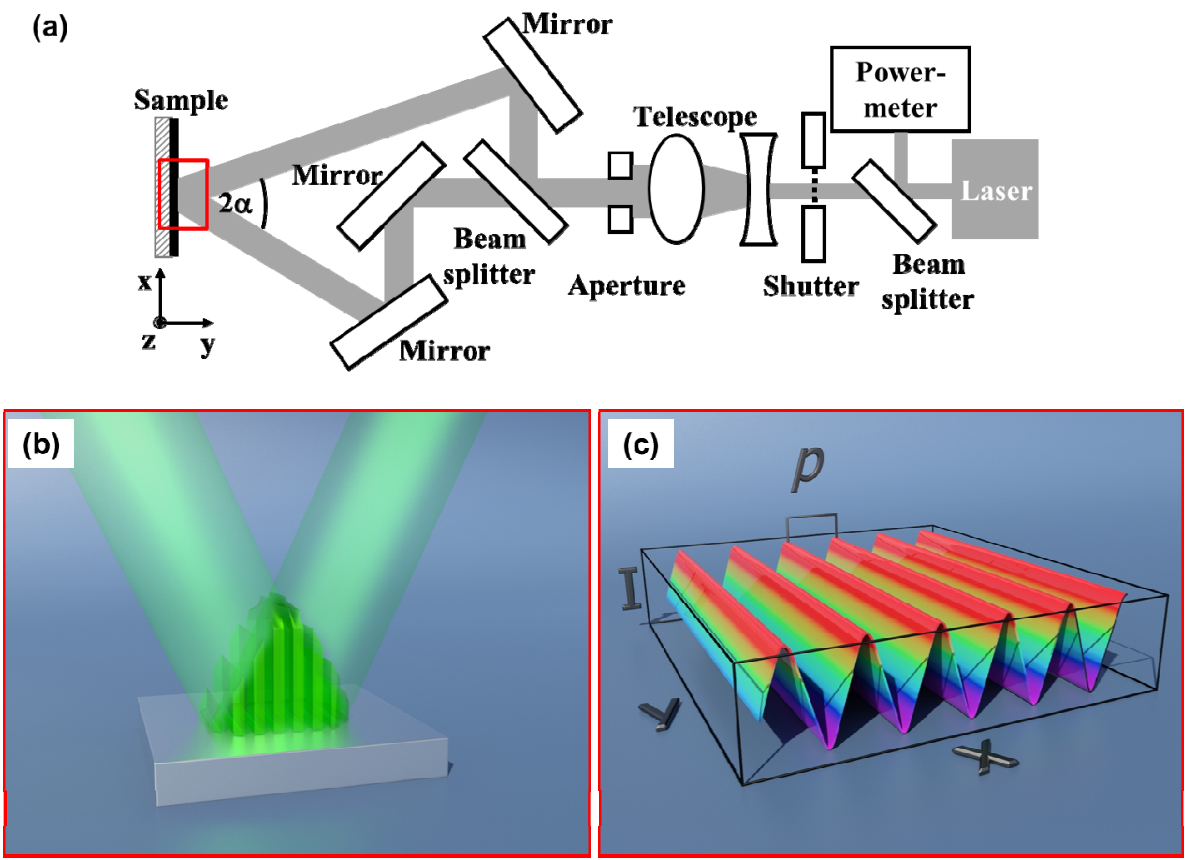

Figure 1. (a) Scheme of the experimental set-up for the Direct Laser Interference Patterning of polystyrene substrates with (b) two interfering beams resulting in (c) a sinusoidal periodic variation of the laser intensity ( $\mathrm{P}$ - periodic distance, I - intensity).

\subsection{Bacterial attachment and biofilm formation}

For the short term bacterial adhesion experiments on polyimide, Staphylococcus epidermidis strain ATCC 1228 were grown at $37^{\circ} \mathrm{C}$ in Luria-Bertani (LB) medium. For the bacterial assays, an overnight culture of S. epidermidis was centrifuged at $3000 \mathrm{~g}$ for $5 \mathrm{~min}$. We removed the supernatant and re-suspended the pellet in phosphate buffer solution (PBS). This washing step was repeated three times. Afterwards, the cell density was adjusted to an OD600 of 0.75 (corresponding to an absolute cell number of $6 \cdot 10^{8} \mathrm{ml}^{-1}$ ). Subsequently, the structured samples were incubated in the bacterial solutions at $37^{\circ} \mathrm{C}$ for $2 \mathrm{~min}(\mathrm{OD} 600=0.75)$ with constant shaking. After the defined time period samples were fixed in $8 \%$ Formol for 15 min, extensively washed with PBS and MilliQ water and dried with nitrogen.

In the case of PS, the clinical Staphylococcus aureus 15981 strain was isolated at the Microbiology Department of the Clínica Universidad de Navarra (Pamplona, Spain) ${ }^{[23]}$. Staphylococci were cultured on tryptic soy agar (TSA) or broth (TSB) at $37^{\circ} \mathrm{C}$ supplemented with glucose $(0.25 \%)$ or with human serum $(10 \%)$ when indicated. Then, an overnight culture of $S$. aureus was diluted with a ratio of 1:100. Two $\mathrm{ml}$ of the diluted culture were added to six-well microtiter plates. We put PS substrates with patterned and initial (reference) topographies in each well. The plates were incubated for 2 hours at $37^{\circ} \mathrm{C}$ with shaking. After incubation the substrates with the attached bacteria were removed from the microtiter plate, gently rinsed three times with sterile PBS, and then placed in $1 \mathrm{ml}$ of PBS and vigorously vortexed. Subsequently, the samples were serially diluted and plated onto TSA plates for enumeration of viable staphylococci (colony forming units, CFU) and biofilm morphology analysis. The relative adhesion was calculated as bacterial counts CFU on patterned surfaces / CFU on non-patterned surfaces.

\subsection{Visualization and topographical characterization}

A scanning electron microscope (Philips XL30 ESEM-SEG, Zeiss Gemini Ultra Plus) with an operating voltage of 3$5 \mathrm{kV}$ was used to visualize the surface of the patterned sample as well as the attached bacteria. A thin gold coating of $10 \mathrm{~nm}$ was sputtered (BALZERS SCD 050 Sputter Coater). on the non-conductive samples to avoid charge processes. 
The topographical analyses for investigating the structure morphology and depth was conducted with a confocal microscope (Leica DCM 3D) using a 150x objective with a lateral and z- resolution of $150 \mathrm{~nm}$ and $2 \mathrm{~nm}$, respectively. Furthermore, structures with periods less than $1 \mu \mathrm{m}$ were investigated using an Atomic Force Microscope (Jeol).

For fluorescence imaging, S. epidermidis bacterial cells were stained with DAPI (4',6-diamidino-2-phenylindole, dihydrochloride, 1:10000, Invitrogen). DAPI-stained samples were imaged with Zeiss Axiotech Optical Microscope (20x and 50x air lens) using a DAPI filter. Images were analyzed using Image J (v. 1.45, Wayne Rasband, NIH USA). The number of cells adhering to the structured substrates was quantified within at least 10 frames per sample with minimum image size $5000 \mu \mathrm{m}^{2}$.

For the epifluorescence analysis of $S$. aureus polystyrene wafers were incubated with $S$. aureus 15981 expressing the green fluorescence protein GFP for $4 \mathrm{~h}$ under static conditions. A wide-field fluorescence microscopy was used for imaging of the cells attached to the PS surfaces. Each surface was visualized using a 100x oil immersion lens and 10 fields of view were randomly chosen for statistical analysis.

\subsection{In vivo model of biofilm infection on PS}

The in vivo modelling was conducted only with polystyrene substrates. It was performed with two different analyses: bacterial contamination on the PS substrates (i) prior and (ii) post implantation. For this purpose, we used patterned and non-patterned PS substrates with a size of $0.5 \times 0.5 \mathrm{~cm}^{2}$. For the prior-implantation tests, the substrates were incubated with $0.5 \mathrm{ml}$ of $1: 100$ overnight dilution of $S$. aureus $15981\left(10^{4}\right.$ colony forming units, CFU) culture for 1 hour at $37^{\circ} \mathrm{C}$ with shaking. The in vivo tests with post-implantation contamination were performed with sterile PS substrates, which were contaminated with $10^{4} \mathrm{CFU}$ S. aureus 15981 by injection two days after intraperitoneal surgery.

Both analyses were conducted with CD1 mice which were anesthetized by intraperitoneal injection of a ketamine/xylazine mixture. After abdominal epilation and antisepsis of the operative field, the animals were operated. An incision of $1.5 \mathrm{~cm}$ in the skin was performed with displacement of the subcutaneous space and opening of the peritoneal cavity. Then, contaminated and non-contaminated, respectively, polymeric surfaces were fixed at the abdominal wall. The peritoneal cavity was closed by suture with $6 / 0$ Monosyn $^{\circledR}$. The animals were put in a warm environment and when awake brought back in their cages. After 5 days post contamination, all animals were sacrificed and the polymeric substrates were extracted and placed in $1 \mathrm{ml}$ of PBS and vigorously vortexed. The samples were serially diluted and plated onto TSA plates for enumeration of viable staphylococci. The relative adhesion was calculated as bacterial counts CFU on patterned surfaces / CFU on non-patterned surfaces.

All animal studies were reviewed and approved by the Comité de Ética, Experimentación Animal y Bioseguridad, of the Universidad Pública de Navarra (approved protocol PI-019/12). The work was carried out at the Instituto de Agrobiotecnología under the principles and guidelines described in European Directive 86/609/EEC for the protection of animals used for experimental purposes.

\section{RESULTS AND DISCUSSION}

\subsection{Design of patterned surfaces by DLIP}

Different line-, and pillar-like patterns with spatial periods between 0.5 and $5.0 \mu \mathrm{m}$ were generated on polyimide (PI) films as well as on polystyrene (PS) substrates with varying thicknesses. The laser fluence for all kinds of patterning was kept constant at $0.5 \mathrm{~J} / \mathrm{cm}^{2}$. Figure 2 and Figure 3 display examples of the differently patterned substrates.

The SEM images of patterned PI presented in Figure 2, clearly show a sharp-edged morphological shape of the line- and pillar-like surface structures for periods of $5 \mu \mathrm{m}$ (Figure 2(a,d)), $1 \mu \mathrm{m}$ (Figure 2(b,e)), and $500 \mathrm{~nm}$ (Figure 2(c,f)) ${ }^{[15]}$. Generally, for characterization of the structure, the aspect ratio resulting from ridge width and structure depth is considered. The latter ones were determined by using confocal microscopy (CFM) and atomic force microscopy (AFM). In this case, the ridge width $\left(\mathrm{w}_{\mathrm{r}}\right)$ and structure depth (ds) vary between $\mathrm{w}_{\mathrm{r}}=117 \mathrm{~nm}$ and $\mathrm{d}_{\mathrm{s}}=0.28 \mu \mathrm{m}$ for $\mathrm{P}=500 \mathrm{~nm}$, and $\mathrm{w}_{\mathrm{r}}=1.55 \mu \mathrm{m}$ and $\mathrm{d}_{\mathrm{s}}=0.92 \mu \mathrm{m}$ for $\mathrm{P}=5 \mu \mathrm{m}$. The aspect ratio is defined as the ratio between the structure depth and the ridge width. Although the structure depth is enhanced for increasing spatial period, the aspect ratio decreases for increasing periodical distance from $2.4(500 \mathrm{~nm})$ to $0.59(5 \mu \mathrm{m})$. 

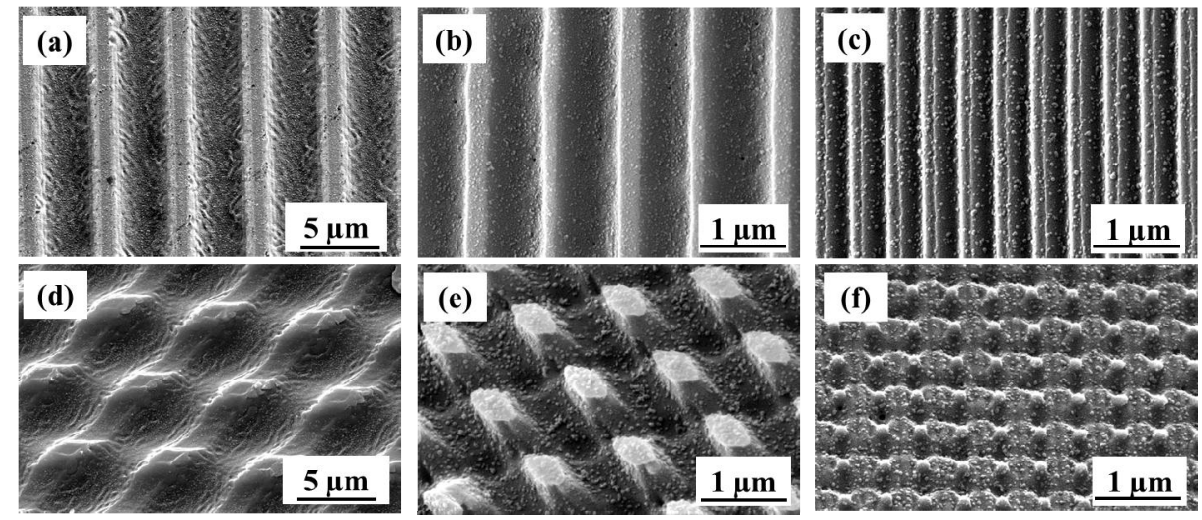

Figure 2. SEM images of differently patterned (a-c: line-like, d-f: pillar-like) PI substrates with (a,d) $\mathrm{P}=5 \mu \mathrm{m},(\mathrm{b}, \mathrm{e}) \mathrm{P}=1.0 \mu \mathrm{m}$, and $(\mathrm{c}, \mathrm{f}) \mathrm{P}=0.5 \mu \mathrm{m}$.

Polymeric materials interact differently with short-pulsed lasers. These interactions are highly complex and strongly depend on the material characteristics. Three main forms of ablation mechanisms can occur during the laser treatment: (1) photo-chemical, (2) photo-thermal, or (3) photo-physical ablation ${ }^{[22,24]}$. A prominent example with predominantly photochemical ablation is polyimide. During UV laser treatment of polyimide a multiphoton excitation process and a photoreaction of the weakly bonded imide groups lead to a photo-chemical decomposition. Chemical analyses reveal that mostly carbon oxides, hydrogen cyanide $(\mathrm{HCN})$, and elemental carbon are the principal products. Furthermore, $\mathrm{C}_{2}$ and $\mathrm{CN}$ are explosively ejected and built bright plasma above the surface which can be detected during the laser shot ${ }^{[25]}$.

However, especially for smaller spatial periods (below $1 \mu \mathrm{m}$ ) roundish shoulders of the sub-microlines are observable (see Figure 2 (c)) also indicating the presence of photo-thermally driven ablation. We assume, that for $355 \mathrm{~nm}$ laser wavelengths at the positions corresponding to the interference maxima (see Figure 1) the glass transition temperature of PI $\left(T_{g}=360-410^{\circ} \mathrm{C}\right)$ is exceeded, inducing reduction of viscosity and density of polyimide (swelling) ${ }^{[26,27]}$. Due to high pressure and strong thermal gradients between interference extrema, this low viscose material is pushed towards the intensity minima forming the shoulders.

In contrast to that, the interaction of laser light with PS is mostly photo-thermally driven ${ }^{[28]}$. During the laser pulse, the photons are repetitively absorbed during a single pulse and the light absorbing molecules (phenyl groups) act like molecular heaters resulting in an increased surface temperature of $370^{\circ} \mathrm{C}\left(\lambda=248 \mathrm{~nm}, \mathrm{~T}_{\mathrm{g}}=100^{\circ} \mathrm{C}\right)^{[22,29]}$. Thus, the material at the positions of the interference maxima forms a melting pool. Similarly to polyimide, the soften material is pushed towards the low temperature interference minima and solidifies. In consequence, a round shaped topography is obtained after the laser pulse, which is presented in Figure 2.
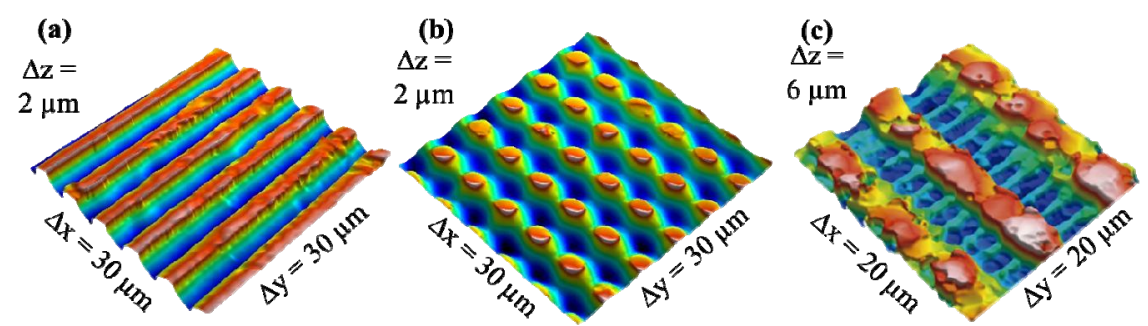

Figure 3. Images from confocal microscopy of PS polymeric surfaces structured by DLIP technique. Periodic arrays of (a) linelike (LN) with $\mathrm{P}=5 \mu \mathrm{m}$, (b) pillar-like (PL) with $\mathrm{P}=5 \mu \mathrm{m}$, and (c) lamella-like (LA) structures with $\mathrm{P}=2 \mu \mathrm{m}^{[30]}$.

After the laser treatment, PS substrates with a thickness of $1.2 \mathrm{~mm}$ exhibit a sinusoidal structure shape with a depth $\left(\mathrm{d}_{\mathrm{s}}\right)$ between $1.63 \pm 0.09$ (lines, Figure 3(a)) and $1.85 \pm 0.1 \mu \mathrm{m}$ (pillars, Figure 3(b)) ${ }^{[30]}$. 
In contrast to the sinusoidal shape on thick PS substrates, similar laser treatment on thin PS films $(125 \mu \mathrm{m})$ creates a line-like structure with periodicities of 6-8 $\mu \mathrm{m}\left(\mathrm{d}_{\mathrm{s}}=4.33 \pm 0.06 \mu \mathrm{m}\right)$ and in between lamellas with a spatial period of $2.0 \mu \mathrm{m}$ and $\mathrm{d}_{\mathrm{s}}=0.47 \pm 0.02 \mu \mathrm{m}$ (see Figure 3(c)). In this case, also mechanical properties play an important role for laser patterning. This quite complex microscale pattern - consisting of larger lines and small lamellas - results from a partially collapse of the line-like features due to the lower mechanical stability of the thin PS film after the second irradiation step ${ }^{[30]}$. With the presented and discussed results we pointed out that DLIP can be used to fabricate different 1D-3D micropatterns on polymeric substrates.

\subsection{In vitro bacterial analyses on patterned polymeric samples}

We conducted two different bacterial attachment tests: (i) S. epidermidis on patterned PI and (ii) S. aureus on PS with 2 min. and $2 \mathrm{~h}$ adhesion time, respectively. Figure 4 summarizes the short-term adhesion test with S. epidermidis on PI.
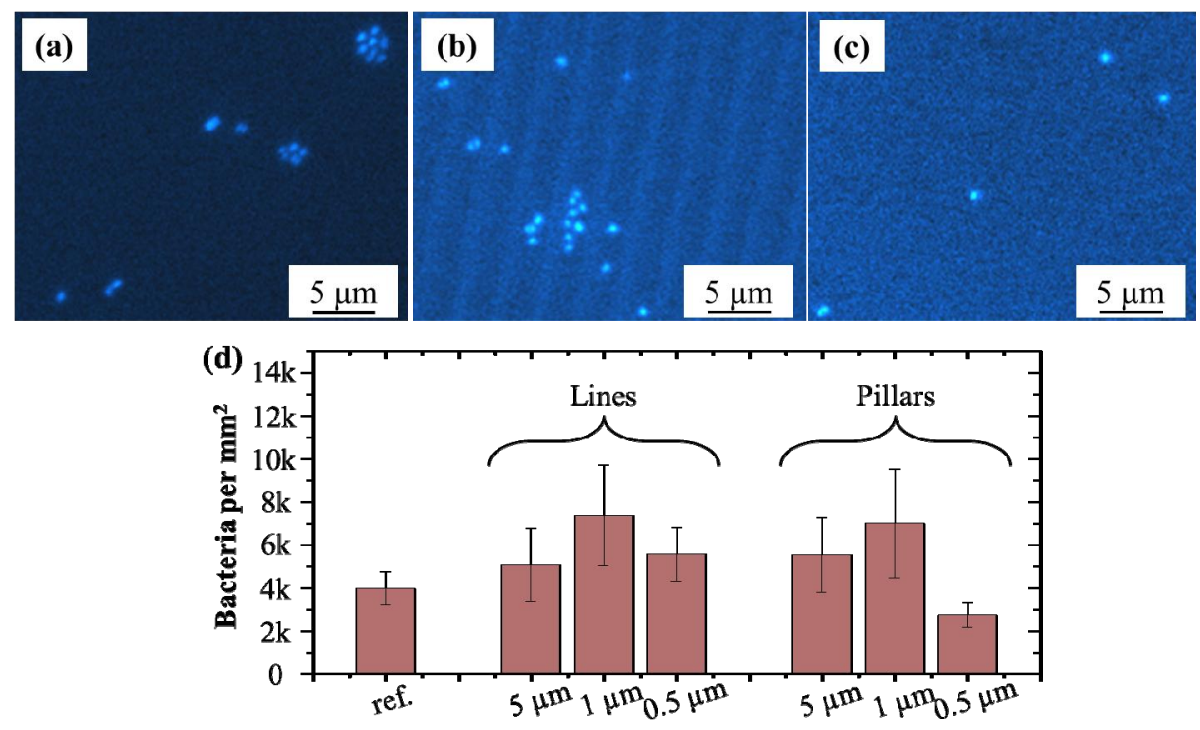

Figure 4. Fluorescence optical images of stained S. epiderimidis microbial strains adhered to PI surfaces (2 min. adhesion time) with (a) smooth topography (reference), (b) line-like micropattern with $\mathrm{P}=1 \mu \mathrm{m}$, and (c) pillar-like micropattern with $\mathrm{P}=0.5 \mu \mathrm{m}$. (d) Number of bacteria attached per square millimeter to microlines and -pillars for different periods compared to the non-treated reference ${ }^{[31]}$.

The fluorescence image in Figure 4(a) shows that already after 2 min. of attachment time, small settlements of two to seven bacteria cells randomly formed on non-patterned PI. Thereby, approx. 4000 cells per $\mathrm{mm}^{2}$ were found. Anisotropic line-like topographies (Figure 4(b)) increased the number of bacteria, whereby cells settled inside the grooves of the structure. Especially, on patterns with a periodic distance of $1 \mu \mathrm{m}$ most bacteria were enumerated $\left(8000 \mathrm{cells} / \mathrm{mm}^{2}\right)$. In contrast, structures with two directions of propagation (2D, pillars) seemed to be less attractive to bacteria than microlines, but still more than smooth surfaces. However, the fewest microorganisms - even less than on a smooth surface - attached to pillars with a periodic distance of $0.5 \mu \mathrm{m}\left(\sim 3000 \mathrm{cells} / \mathrm{mm}^{2}\right)$.

The initial adhesion tests $(2 \mathrm{~h})$ under static condition with $S$. aureus adhered on PS substrates showed similar results. Figure $5(\mathrm{a}-\mathrm{c})$ and $(\mathrm{d})$ presents the qualitative $(\mathrm{SEM})$ and quantitative analyses ${ }^{[30]}$. For the latter one, the number of bacteria to the surface was determined by serial dilution and plating.

In Figure 5(b), SEM images of the contaminated PS surfaces show that after $2 \mathrm{~h}$ significantly more bacteria cells were observed on pillar-like PS surface structures than to non-patterned PS (Figure 5(b)). The micrographs reveal large bacterial aggregates adhered to not only to the top of those structures but also inside the features. On the contrary, small bacteria clusters scattered on complex lamella-like patterns (Figure 5(c)) as well as non-patterned PS. 

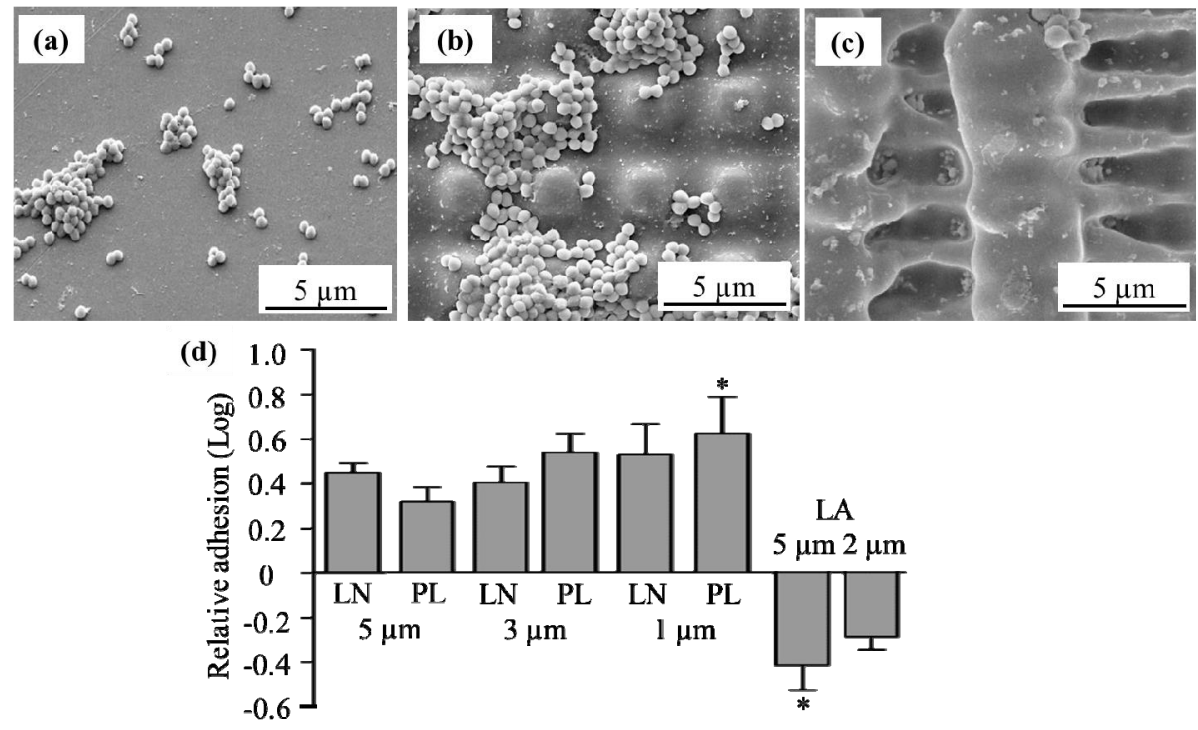

Figure 5. (a-c) Qualitative evaluation of S. aureus 15981 attachment (static conditions, $2 \mathrm{~h}$ ) to (a) smooth reference compared to (b) pillar- $(3 \mu \mathrm{m})$ and (c) lamella-like $(2 \mu \mathrm{m})$ patterned PS. (d) Relative adhesion (colony forming units (CFU) on patterned surfaces/CFU on non-patterned surfaces) of $S$. aureus on PS surfaces with line (LN), pillar (PL), and lamella (LA) micrometer structures and different periodical distances. Multiple comparisons were performed by one-way analysis of variance combined with the Bonferroni multiple comparison test (GraphPad Instat, version 5). Asterisks indicate significant adhesion differences $(\mathrm{R} \leq 0.05 \text { [significant] })^{[30]}$

In addition, the relative adhesion of the bacteria determined as the ratio of colony forming units on patterned to CFU on no-patterned surfaces is depicted in Figure 5(d). It can be seen, that for all line- and pillar-like topographies the number of bacteria increased compared to smooth PS surfaces. Particularly, spatial periods of $1 \mu \mathrm{m}$ induced higher bacterial attachment $(\mathrm{R}<0.05)$ than 3 or $5 \mu \mathrm{m}$. However, lamella patterns with 5 and $2 \mu \mathrm{m}$ periods decreased CFUs related to non-patterned PS ${ }^{[30]}$.

Both, attachment numbers and patterns on PI and PS suggest that bacteria seem to be hindered from initial attachment to the surface if the pattern possesses a certain complexity (pillars and lamella) and spatial period, which are either considerably larger (lamella, $5 \mu \mathrm{m}$ ) or smaller (pillars, $0.5 \mu \mathrm{m}$ ) than the cells. It is assumed, that those surfaces offer fewer adhesion points to the microorganisms and thus, bacteria easily detach from structure tops due to increased shear forces by turbulent liquid flow during the washing process ${ }^{[32]}$. Especially, within line-like topographies cells are able to settle in structure grooves, where they are protected from shear forces. Furthermore, for periodic distances close to the bacteria dimensions (S. epidermidis: $\sim 1 \mu \mathrm{m}$, S. aureus: 0.8-1.2 $\mu \mathrm{m}$ ) the microorganisms maximize the contact area with the surface (in this study: $1 \mu \mathrm{m}$ ), while smaller periods (here: $0.5 \mu \mathrm{m}$ ) reduce the net contact area cell/surface resulting in decreased bacterial attachment ${ }^{[32]}$.

\subsection{In vivo biofilm formation model on PS surfaces}

In our work, in vivo studies on the biofilm formation were conducted on the most promising surface topography (lamellas) on polystyrene material (PS) to prove the reliability of the above shown results. Thereby, two infection models were executed: (i) prior and (ii) post implantation of the substrate. After five days post contamination, the mice were sacrificed, to aseptically removed the polystyrene wafers and evaluate the bacterial load (Figure 6(a,b).

The graph in Figure 6(c) shows that the previously described trend pursues. Compared to the non-patterned reference $(\mathrm{R}<0.01)$, in both cases a significant reduction on bacterial attachment/biofilm generation was obtained on the lamellalike PS whether infection has occurred during surgical procedure or post implantation ${ }^{[30]}$. 

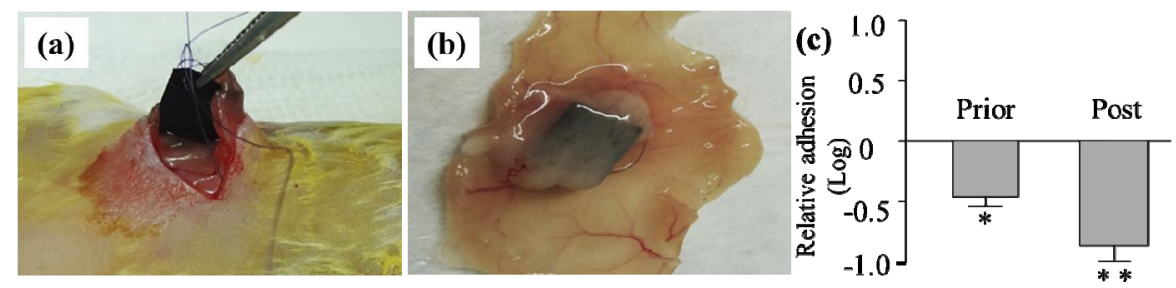

Figure 6. Biofilm formation of Staphylococcus aureus on lamella-like patterned PS surfaces using an in vivo model. (a) Implantation of substrates in the intraperitoneal cavity of CD1 mice. (b) Biofilm-infected surfaces after 5 days of infection. (c) Relative adhesion (CFU patterned/CFU nonpatterned) on lamella-like patterned PS surfaces with $2 \mu \mathrm{m}$ periodic distance contaminated with S. aureus prior (104 CFU) and post (108 CFU) implantation ${ }^{[30]}$.

\section{SUMMARY}

In this work, we demonstrated the potential of the Direct Laser Interference Patterning method as a highly flexible technology to rapidly provide polymeric surfaces (polyimide and polystyrene) with ordered micro- and sub-micrometer scale topographies. Depending on the material properties and interaction with the laser light, various structure morphologies like lines, pillar, or lamellas could be fabricated. Subsequently, the differently patterned polyimide and polystyrene were used for bacterial adhesion tests. We showed that in vitro less $S$. epidermidis and $S$. aureus bacteria adhered on patterns with a higher degree of complexity (pillars and lamellas) compared to line-like patterns. Thereby, significant fewer cells were enumerated on pillar-like patterns with $0.5 \mu \mathrm{m}$ spatial period on PI as well as lamella-like morphologies on PS compared to the smooth reference surfaces. Furthermore, the trend described for the in vitro tests pursued for in vivo experiments with most promising lamella patterns on PS.

\section{ACKNOWLEDGMENT}

J. Valle was supported by Spanish Ministry of Science and Innovation "Ramón y Cajal" contract. This research was supported by grants AGL2011-23954 and BIO2011-30503-C02-02 from the Spanish Ministry of Economy and Competitivity and IIQ14066.RI1 from Innovation Department of the Government of Navarra. A. Lasagni, D. Günther, and R. Helbig thank the Deutsche Forschungsgemeinschaft for the financial support of the project "Mechanically stable anti-adhesive polymer surfaces" (LA-2513 4-1, WE 2539/17-1).

\section{REFERENCES}

[1] Hasan, J., Crawford R.J., Ivanova E.P., "Antibacterial surfaces: the quest for a new generation of biomaterials," Trends Biotechnol 31, 295-304 (2013).

[2] Knetsch, M.L.W., Koole, L.H., "New Strategies in the Development of Antimicrobial Coatings: The Example of Increasing Usage of Silver and Silver Nanoparticles," Polymers 3, 340-366 (2011).

[3] Shah, S.R., Tatara A.M., D'Souza, R.N., Mikos, A.G., Kasper, F.K., "Evolving strategies for preventing biofilm on implantable materials," Materials Today 16, 177-182 (2013).

[4] Basak, P., Adhikari, B., Banerjee, I., Maiti, T.K., "Sustained release of antibiotic from polyurethane coated implant materials," J. Mater. Sci. Mater. Med. 20 Suppl. 1, S213-S221 (2009.

[5] Francolini, I., D'Ilario, L., Guaglianone, E., Donelli, G., Martinelli, A., "Polyurethane anionomers containing metal ions with antimicrobial properties: thermal, mechanical and biological characterization," Acta Biomater 6, 3482-3490 (2010).

[6] Boyd, R.D., Verran, J., Jones, M.V., Bhakoo, M.," Use of the Atomic Force Microscope To Determine the Effect of Substratum Surface Topography on Bacterial Adhesion," Langmuir 18, 2343-2346 (2002).

[7] Whitehead, K.A., Verran J., "The effect of surface topography on the retention of microorganisms," Food Bioprod. Process 84, 253-259 (2006). 
[8] Whitehead, K.A., Rogers, D., Colligon, J., Wright, C., Verran, J., "Use of the atomic force microscope to determine the effect of substratum surface topography on the ease of bacterial removal," Colloids Surf. B Biointerfaces 51, 44-53 (2006).

[9] Park, B., Nizet, V., Liu, G.Y., "Role of Staphylococcus aureus catalase in niche competition against Streptococcus pneumonia," J. Bacteriol. 190, 2275-2278 (2008).

[10] Abban, S., Jakobsen, M., Jespersen, L., "Attachment behaviour of Escherichia coli K12 and Salmonella Typhimurium P6 on food contact surfaces for food transportation," Food Microbiol. 31, 139-147 (2012).

[11] Biswas, A., Bayer, I.S., Biris, A.S., Wang, T., Dervishi, E., "Advances in top-down and bottom-up surface nanofabrication: techniques, applications \& future prospects," Adv. Colloid. Interface Sci. 170, 2-27 (2012).

[12] Kim, P., Epstein, A.K., Khan, M., Zarzar, L.D., Lipomi, D.J., "Structural transformation by electrodeposition on patterned substrates (STEPS): a new versatile nanofabrication method," Nano Lett. 12, 527-533 (2012).

[13] Graham, M.V., Mosier, A.P., Kiehl, T.R., Kaloyeros, A.E., Cady, N.C. "Development of antifouling surfaces to reduce bacterial attachment," Soft Matter 9, 6235 (2013).

[14] Manabe, K., Nishizawa, S., Shiratori, S. "Porous surface structure fabricated by breath figures that suppresses Pseudomonas aeruginosa biofilm formation," ACS Appl. Mater. Interfaces 5, 11900-11905 (2013).

[15] Langheinrich, D., Yslas, E., Broglia, M., Rivarola, V., Acevedo, D., Lasagni A., "Control of Cell Growth Direction by Direct Fabrication of Periodic Micro- and Submicrometer Arrays on Polymers," J. Polymer Sci. Part B 50, 415-422 (2012).

[16] Bieda, M., Beyer, E., Lasagni, A., "Direct Fabrication of Hierarchical Microstructures on Metals by Means of Direct Laser Interference Patterning,” J. Eng. Mat. Tech. 132, 031015 (2010).

[17] Berger, J., große Holthaus, M., Pistillo, N., Roch, T., Kurosch, R., Lasagni, A., "Ultraviolet laser interference patterning of hydroxyapatite surfaces,” Appl. Surf. Sci. 257 (7), 3081-3087 (2011).

[18] Graham, M., Cady, N., "Nano and Microscale Topographies for the Prevention of Bacterial Surface Fouling," Coatings 4, 37-59 (2014).

[19]Bieda, M., Schmädicke, C., Roch, T., Lasagni, A., "Ultra-Low Friction on 100Cr6-Steel Surfaces After DirectLaser Interference Patterning," Adv. Eng. Mater. 17 (1), 102-108 (2015).

[20] Lasagni, A.F., Roch, T., Berger, J., Kunze, T., Lang, V., Beyer, E., "To use or not to use (direct laser interference patterning), that is the question," Proc. of SPIE Vol. 9351, 935115 (2015).

[21] Srinivasan, R., Braren, B., "UV laser ablation of organic polymers," Chem. Rev. 89, 1303-1316 (1989).

[22] Lazare, S., Granier, V., "Ultraviolet laser photoablation of polymers: a review and recent results," Laser Chem. 10, 25-40 (1988).

[23] Valle, J., Toledo-Arana, A., Berasain, C., Ghigo, J.-M., Amorena, B., "SarA and not sigmaB is essential for biofilm development by Staphylococcus aureus," Mol. Microbiol. 48, 1075-1087 (2003).

[24] Lasagni, A., Cornejo, M., Lasagni, F., Mücklich, F., "Laser ablation modeling of periodic pattern formation on polymer substrates," Adv. Eng. Mater. 10 (5), 488-493 (2008).

[25] Srinivasan, R., Braren, B., Dreyfus, R., "Ultraviolet laser ablation of polyimide films," J. Appl. Phys. 61 (1), 372-376, (1987).

[26] Yung, W., Liu, J., Man, H., Yue, T., "355 nm Nd:YAG laser ablation of polyimide and its thermal effect," J. Mater. Proc. Technol. 101, 306-311 (2000).

[27] Urech, L., Lippert, T., [Photochemistry and Photophysics of Polymer Materials], John Wiley \& Sons, 541-567 (2010).

[28] Madorsky, S.L., Strauss, S., "Pyrolytic fractionation of polystyrene in a high vacuum and mass spectrometer analysis of some of the fractions," J. Research Nation Bureau of Stand 40, 417 (1948).

[29] Lasagni, A., Acevedo, D., Barbero, C. Mücklich, F. "Direct patterning of polystyrene-polymethyl methacrylate copolymer by means of laser interference lithography using UV laser irradiation," Poly. Eng. Sci. 48 (12), 2367-2372, (2008).

[30] Valle, J., Burgui, S., Langheinrich, D., Gil, C., Solano, C., Toledo-Arana, A., Helbig, R., Lasagni, A., Lasa, I., "Evaluation of surface microtopography engineered by direct laser interference for bacterial anti-biofouling," Macromol. Biosci. 15, 1060-1069 (2015).

[31] Günther, D., Scharnweber, D., Hess, R., Wolf-Brandstetter, C., grosse Holthaus, M., Lasagni, A.F., [Laser Surface Modification of Biomaterials], Elsevier Ltd., accepted (2016).

[32] Helbig, R., Günther, D., Friedrichs, J., Lasagni A., Werner, C., "Slowdown bacterial colonization by sub-cell sized topographies," submitted (2015). 